CDD: 617.6

\title{
CIRURGIA PERIODONTAL PARA O RESTABELECIMENTO DAS DISTÂNCIAS BIOLÓGICAS: RELATO DE UM CASO CLÍNICO
}

\author{
PERIODONTAL SURGERY FOR BIOLOGICAL WIDTH \\ RE-ESTABLISHMENT: A CASE REPORT
}

\author{
FÁBIO ANDRÉ DOS SANTOS ${ }^{1}$ \\ RAFAEL SARTORI ${ }^{2}$ \\ 1 Professor do Departamento de \\ Odontologia da UEPG e UNIPAR \\ 2 Cirurgião Dentista, Estagiário da \\ Disciplina de Periodontia - UEPG
}

\begin{abstract}
RESUMO
Situações clínicas em que temos términos de preparos subgengivais, nem sempre nos permitem realizar os procedimentos restauradores dentro dos adequados padrões técnicos e biológicos. Faz-se necessário, muitas vezes, procedimentos cirúrgicos periodontais para viabilizar os procedimentos restauradores. O periodonto quando sadio apresenta uma distância biológica que compreende o espaço entre a base do sulco gengival histológico e a crista óssea alveolar. Este deve ser respeitado durante os procedimentos restauradores, para que se tenha manutenção da saúde periodontal. Várias técnicas cirúrgicas periodontais podem ser utilizadas para o restabelecimento das distâncias biológicas. Entre elas temos: gengivectomia e retalhos periodontais, com ou sem osteotomia. Este trabalho se propõe a apresentar a técnica e o resultado de um caso clínico em que foi realizada uma cirurgia periodontal para restabelecimento das distâncias biológicas com o objetivo de
\end{abstract}


90

viabilizar o tratamento restaurador.

Palavras-chave: Cirurgia periodontal; distâncias biológicas; aumento de coroa clínica

\section{Introdução}

As restaurações de dentes que apresentam lesões de cárie ou fraturas coronárias devem devolver ao paciente a função e a estética, respeitando a saúde das estruturas periodontais e também viabilizando os procedimentos de higienização por parte do paciente (BRÄGGER et al., 1992; DE WAAL e CASTELLUCCI, 1993; MAYNARD e WILSON, 1979; NEVINS, 1982; NEVINS e SKUROW, 1984; WAGENBERG et al., 1989).

Situações clínicas, como cáries com extensão subgengival, trepanações radiculares ou fraturas dentais, nem sempre nos permitem realizar os procedimentos restauradores dentro dos padrões técnicos, sendo muitas vezes necessário procedimentos cirúrgicos periodontais para viabilizar os procedimentos restauradores (DE WAAL e CASTELLUCCI, 1994; NEVINS, 1982; NEWCOMB, 1974; PALOMO e KOPCZYK, 1978; WILSON e MAYNARD, 1981).

O periodonto, quando sadio, apresenta uma distância biológica que compreende o espaço entre a base do sulco gengival histológico e a crista óssea alveolar. A existência dessa distância é fundamental para a aderência do epitélio juncional e a inserção de fibras conjuntivas da gengiva, à estrutura dentária. Essa distância deve ser respeitada durante os procedimentos restauradores (MAYNARD e WILSON, 1979; NEVINS, 1982; PALOMO e KOPCZYK, 1978; SIVERS e JOHNSON, 1985; WAGENBERG et al., 1989).

Gargiulo et al. (1961) realizaram um estudo analisando as distâncias biológicas e concluíram que em média a profundidade do sulco gengival foi de $0,69 \mathrm{~mm}$, o cumprimento do epitélio juncional $0,97 \mathrm{~mm}$ (variando de 0,71 para $1,35 \mathrm{~mm}$ ) e a inserção das fibras gengivais ocupavam $1,07 \mathrm{~mm}$ (variando 1,06 para $1,07 \mathrm{~mm}$ ) da superfície radicular. Portanto, o espaço localizado coronariamente à crista óssea alveolar pode ser arredondado para aproximadamente $3,0 \mathrm{~mm}$. No entanto, esta medida pode variar de dente para dente e na mesma face de um mesmo dente, estando presente em toda 
a dentição saudável.

Tristão (1992) estudou as distâncias biológicas por meio de análise histométrica em periodonto de humanos clinicamente saudáveis. A média da margem gengival ao topo da crista óssea alveolar foi de 2,75mm com variações entre 2,16 a 3,34mm. Esses resultados foram semelhantes aos encontrados por Gargiulo et al. (1961), confirmando assim, através de um trabalho "in vivo", o valor médio de 3,0mm para as distâncias biológicas. Essa medida pode ser usada como referência nos procedimentos clínicos.

Para que um procedimento restaurador não cause dano aos tecidos periodontais, o término do preparo deve estar localizado entre 3 a $4 \mathrm{~mm}$ da crista óssea alveolar, preservando assim o epitélio juncional e o tecido conjuntivo gengival. Se o preparo cavitário ou protético invadir essa área, ocorrerá uma resposta inflamatória, que poderá resultar na formação de uma bolsa periodontal com reabsorção óssea e/ou hiperplasia gengival (DE WAAL e CASTELLUCCI, 1993; SIVERS e JOHNSON, 1985; WILSON e MAYNARD, 1981).

Alguns autores consideram o sulco gengival como uma estrutura integrante das distâncias biológicas, pois os procedimentos clínicos não podem ignorá-lo, principalmente por apresentar uma medida muito variável nas diferentes faces de um mesmo dente e ainda, restaurações com margens localizadas subgengivalmente apresentaram maior inflamação gengival quando comparadas com dentes hígidos (ASSIF et al., 1981; GARGIULO et al., 1961; NEWCOMB, 1974). No entanto, outros autores não consideram o sulco gengival como um constituinte do espaço biológico, visto que o mesmo pode ser invadido por procedimentos restauradores (BAIMA, 1986; DE WAAL e CASTELLUCCI, 1993; FESTUGATO et al., 2000; MAYNARD e WILSON, 1979).

Os procedimentos cirúrgicos para o restabelecimento das distâncias biológicas estão indicados em situações como nos casos de lesões cariosas localizadas subgengivalmente, fraturas dentais invadindo a distância biológica, exposição de estrutura radicular para o isolamento absoluto, trepanação cervical durante o tratamento endodôntico. Como contra-indicações, temos situações em que a osteotomia durante a cirurgia poderia expor a furca em dentes multirradiculares, comprometer a estética em dentes anteriores ou ainda causar defeitos ósseos nos dentes adjacentes. Ainda podemos considerar dentes com grandes perdas de inserção periodontal, raízes dentárias curtas e cônicas, cáries muito extensas e fraturas ou perfuração radiculares localizadas nos terços médio ou apical (ASSIF et al., 1981; BAIMA, 1986; 
92

DE WAAL e CASTELLUCCI, 1993; PALOMO e KOPCZYK, 1978).

Ao longo dos anos várias técnicas cirúrgicas foram desenvolvidas para o tratamento da doença periodontal e adaptadas para o restabelecimento das distâncias biológicas ou para ambos concomitantemente, entre elas temos: gengivectomia, retalhos periodontais associados ou não com osteotomia e inter-relação entre os procedimentos cirúrgicos periodontais e a ortodontia (DE WAAL e CASTELLUCCI, 1994; PALOMO e KOPCZYK, 1978; SIVERS e JOHNSON, 1985; WAGENBERG et al., 1989).

Este trabalho se propõe a apresentar a técnica e o resultado de um caso clínico, em que foi realizada uma cirurgia periodontal, para restabelecimento das distâncias biológicas com o objetivo de viabilizar o tratamento restaurador.

\section{Caso clínico}

O paciente M.L.F., 32 anos, foi encaminhado à Clínica de Extensão do Guaragi, da Universidade Estadual de Ponta Grossa (UEPG), para tratamento odontológico. Na anamnese, o mesmo mostrou boas condições sistêmicas e, no exame clínico, não apresentava profundidades de sondagem maiores que $4 \mathrm{~mm}$, porém possuía alguns sítios com inflamação gengival e presença de poucos fatores de retenção de placa bacteriana (cálculo). Observou-se ainda lesão cariosa envolvendo as faces oclusal e distal no dente 15, com hiperplasia do tecido gengival para o interior da cavidade (figura 1).

O exame radiográfico revelou que o dente apresentava um comprometimento endodôntico, adequada estrutura dental remanescente e ausência de defeitos ósseos. A distância entre o término da lesão cariosa e a crista óssea, sugeria invasão das distâncias biológicas (figura 2). Como conduta de tratamento, ainda na primeira sessão, foram realizados: raspagem, alisamento radicular, polimento coronário e orientação de higiene bucal.

Na segunda sessão, foi realizado um retalho periodontal para o restabelecimento das distâncias biológicas. Como conduta pré-operatória, foi ministrado ao paciente, 1 hora antes do procedimento, $4 \mathrm{mg}$ de dexametasona em dose única (Decadron ${ }^{\circledR}$ ) como agente antiinflamatório. Após a anestesia infiltrativa (mepivacaíana com adrenalina 1:100.000), foi feita uma incisão em bisel interno, utilizando um bisturi com lâmina 15, 
sendo então descolado um retalho em espessura total, tanto pela vestibular como pela palatina. Após esse procedimento, com uma cureta periodontal, realizou-se a remoção do tecido inflamatório, deixando a crista óssea alveolar bem nítida. Em seguida, com uma sonda periodontal verificou-se a medida da distância biológica (3mm). Neste caso a medida da crista óssea até o término do preparo foi menor que $3 \mathrm{~mm}$, sendo necessária a remoção de tecido ósseo na porção distal.

A remoção de tecido ósseo na interproximal foi feita com uma lima de Schluger n. 9-10. A osteoplastia nas faces vestibular e palatina foi realizada com um cinzel de Rhodes n. 36-37. Após a osteotomia realizou-se novamente a medição da crista óssea até o término do preparo, verificandose assim os 3mm obtidos (figura 3).

Após abundante irrigação com solução fisiológica a 0,9\%, foi realizada uma sutura do tipo sutura circunferencial simples, utilizando fio de seda 4-0 (Ethicon $\left.{ }^{\circledR}\right)$, portanto não foi utilizado cimento cirúrgico.

No pós-operatório foram prescritos dois bochechos diários com solução de digluconato de clorexidina $(0,12 \%)$ durante uma semana devido à impossibilidade de realizar o controle mecânico da placa bacteriana na área submetida ao procedimento cirúrgico. Também foi prescrito o uso de analgésico para o controle da dor (paracetamol 750mg de 4/4 horas, durante 3 dias).

As suturas foram removidas após 7 dias, sendo então restituídos os procedimentos mecânicos de controle de placa. Nesse momento, o canal radicular foi instrumentado e aplicado um curativo de demora à base de hidróxido de cálcio e propilenoglicol. Após 45 dias da cirurgia, foi concluído o tratamento endodôntico, as paredes do preparo cavitário foram protegidas com cimento de ionômero de vidro (figura 4) e então realizada a restauração definitiva com amálgama (figuras 5 e 6).

Todos os procedimentos foram realizados com o pleno consentimento do paciente.

\section{Discussão}

Para a realização de uma restauração é muito importante que se respeite a integridade do periodonto, principalmente naquela situação em que ocorre extensão da margem para a região subgengival. Dentro da odontolo- 
gia restauradora é muito comum nos defrontarmos com situações em que os términos dos preparos se estendem para a região subgengival, dificultando assim a realização de restaurações dentro dos padrões ideais (ASSIF et al., 1981; BAIMA, 1986; DE WAAL e CASTELLUCCI, 1993; MAYNARD e WILSON, 1979; NEVINS e SKUROW, 1984; WAGENBERG et al., 1989; WILSON e MAYNARD, 1981).

O epitélio juncional e as fibras colágenas do tecido gengival, compõem o que chamamos de distância biológica. Portanto esta se estende da base do sulco histológico até o topo da crista óssea alveolar (BRÄGGER et al., 1992; GARGIULO et al., 1961; MAYNARD e WILSON, 1979; TRISTÃO, 1992). No entanto essa medida pode variar de dente para dente e na mesma face de um mesmo dente. Se considerarmos que essa área é variável, julgamos prudente que a distância entre o término de um preparo protético à crista óssea varie de 3 a 4mm (ASSIF et al., 1981; BAIMA, 1986; DE WAAL e CASTELLUCCI, 1993; SIVERS e JOHNSON, 1985; WILSON e MAYNARD, 1981).

O sulco gengival, segundo alguns autores, não faria parte do espaço biológico, visto que o mesmo pode ser invadido durante os procedimentos restauradores (BAIMA, 1986; DE WAAL e CASTELLUCCI, 1993; FESTUGATTO et al., 2000; MAYNARD e WILSON, 1979). Porém estudos mostram, que o sulco gengival apresenta variações de dente para dente e até mesmo nas diferentes faces de um mesmo dente (ASSIF et al., 1981; GARGIULO et al., 1961). Restaurações com margens localizadas subgengivalmente apresentaram maior inflamação gengival quando comparadas com dentes hígidos (NEWCOMB, 1974). Portanto o sulco gengival, juntamente com o epitélio juncional e fibras do tecido conjuntivo gengival, deveriam ser considerados como uma estrutura integrante do que chamamos de espaço biológico, sendo esta a única que pode ser violada durante os procedimentos clínicos e mesmo assim com muita cautela.

Muitas técnicas cirúrgicas periodontais podem ser utilizadas para se obter o restabelecimento das distâncias biológicas, entre as quais temos: gengivectomia, retalhos periodontais associados ou não com osteotomia (ASSIF et al., 1981; BAIMA, 1986; BRÄGGER et al., 1992; SIVERS e JOHNSON, 1985).

Em nosso caso clínico através do exame radiográfico, observamos uma quantidade adequada de estrutura dentária remanescente e ausência de perda óssea. A distância que existia entre o término da lesão cariosa e a crista óssea, sugeria a possível necessidade de uma cirurgia periodontal 
com osteotomia na região interproximal, no entanto a radiografia não é um meio muito fidedigno para diagnosticar a invasão das distâncias biológicas (FESTUGATTO et al., 2000). Para a recuperação das distâncias biológicas optamos pela realização de cirurgia periodontal utilizando uma incisão em bisel interno e rebatimento de um retalho total. Um bisel interno permitiu a manutenção da largura da mucosa ceratinizada. A realização de um bisel mais extenso com a remoção de $1-2 \mathrm{~mm}$ de tecido gengival não foi realizado, pois a largura da mucosa ceratinizada era pequena (3mm) e também seria desnecessário, pois nossa área de interesse era a região interproximal (DE WAAL e CASTELLUCCI, 1994; PALOMO e KOPCZYK, 1978).

A osteotomia foi realizada com instrumentos manuais (cinzel de Rhodes n.36-37 e lima de Schluger n.9-10), pode-se também obter resultados semelhantes com a utilização de brocas com alta rotação sob abundante irrigação ou ainda associação de instrumentos rotatórios com os manuais (DE WAAL e CASTELLUCCI, 1994; NEVINS e SKUROW, 1984; WAGENBERG et al., 1989). Porém nos casos de cirurgia para o restabelecimento de distâncias biológicas, em geral a remoção de tecido ósseo é muito pequena, portanto o uso de instrumentos manuais foi adequado.

Após o procedimento cirúrgico, o tempo de espera para a realização do tratamento restaurador deve ser de aproximadamente de 45 a 60 dias. É nesse período que a margem deve ser repreparada e ajustada, porém em regiões em que a estética não é importante o tratamento restaurador pode ser realizado em um tempo menor (DE WAAL e CASTELLUCCI, 1994; NEVINS e SKUROW, 1984; PALOMO e KOPCZYK, 1978; SIVERS e JOHNSON, 1985). Brägger et al. (1992) observaram que as modificações na posição da margem gengival foram mínimas após 6 semanas e 6 meses, sendo que do total de sítios analisados, apenas $12 \%$ tiveram alterações na posição da gengiva marginal.

Pôde-se observar que o procedimento cirúrgico para o restabelecimento da distância biológica foi efetivo, pois viabilizou o tratamento endondôntico, bem como a restauração definitiva, respeitando a integridade dos tecidos periodontais e contribuindo para resultados satisfatórios mais duradouros. 


\title{
4. Conclusão
}

Os procedimentos para restabelecimento da distância biológica, quando devidamente indicados, possibilitam a realização de procedimentos restauradores adequados, mantendo a integridade dos tecidos periodontais.

Restaurações com margens bem adaptadas, contribuem para facilitar o adequado controle da placa bacteriana por parte do paciente, aumentando assim a longevidade dos procedimentos restauradores.

Recebido para publicação em 10/03/00.

Aceito para publicação em 10/06/00.

\begin{abstract}
The clinical conditions that we have subgingival margin extension of, not always it allows to make the restorative dentistry inside of the technical and biological patterns. Being a lot of times necessary periodontal surgical procedures, to make possible the restorative procedures. The periodontal tissue when healthy, present a biological width (connective tissue attachment plus junctional epithelium), this should be respected during the restorative dentistry and for the periodontal health maintenance. Several periodontal surgery techniques can be used for the reestablishment of the biological width, such as: gengivectomy, periodontal flaps and osseous surgery. This paper shows the technique and the clinical case result in that a periodontal surgery was accomplished for re-establishment of the biological width with the objective of making possible the restorative dentistry.
\end{abstract}

Key words: Periodontal surgery; biological width; surgical crown lengthening

\author{
Endereço para contato: Fábio André dos Santos \\ Rua Afonso Pena, n. 525, Ap.32, CEP-84040-170, \\ Vila Estrela, Ponta Grossa/PR. \\ fasantos@interponta.com.br
}




\section{REFERÊNCIAS}

1 ASSIF, D.; PILO, R.; MARSHAK, B. Restoring teeth following lengthening procedures. J. Prosthet. Dent., v. 65, n. 1, p. 62-64, Jan. 1981.

2 BAIMA, R. F. Extension of clinical crown length. J. Prosthet. Dent., v. 55, n. 5, p. 547-551, May 1986.

3 BRÄGGER, U.; LAUCHENAUER, D.; LANG, N. P. Surgical lengthening of the clinical crown. J. Clin. Periodontol., v. 19, n. 1, p. 58-63, Jan. 1992.

4 DE WAAL, H.; CASTELLUCCI, G. The importance of restorative margin placement to the biologic width and periodontal health. Part. I. Int. J. Periodont. Rest., v. 13, n. 5, p. 460-471, 1993.

5 DE WAAL, H.; CASTELLUCCI, G. The importance of restorative margin placement to the biologic width and periodontal health. Part. II. Int. J. Periodont. Rest., v. 14, n. 1, p.70-83, Feb. 1994.

6 FESTUGATTO, F. E.; DAUDT, R. L.; RÖSING, C. K. Aumento de coroa clínica: comparação de técnicas de diagnóstico de invasão do espaço biológico do periodonto. Periodontia, v. 9, n. 1, p. 42-49, Jan.-Jun. 2000.

7 GARGIULO, A. W.; WENTZ, F. M.; ORBAN, B. Dimensions and relations of the dentogingival junction in humans. J. Periodontol., v. 32, n. 3, p. 261-267, Jul. 1961.

8 MAYNARD JR., J. G.; WILSON, R. D. K. Physiologic dimensions of the periodontium significant to restorative dentist. J. Periodontol., v. 50, n. 4, p.170174, Apr. 1979.

9 NEVINS, M. Interproximal periodontal disease: the embrasure as an etiologic factor. Int. J. Periodont. Res., v. 2, n. 6, p. 8-27, 1982.

10 NEVINS, M.; SKUROW, H. M. The intracrevicular restorative margin, the biologic width and maintenance of gingival margin. Int. J. Periodont. Res., v. 4, n. 3, p. 30-49, 1984.

11 NEWCOMB, G. M. The relationship between the location of subgingival crown margins and gingival inflamation. J. Periodontol., v. 45, n. 3, p. 151-154, Mar. 1974. 
12 PALOMO, F.; KOPCZYK, R. Rationale and methods for crown lengthening. J. Am. Dent. Assoc., v. 96, n. 2, p. 257-60, Feb. 1978.

13 SIVERS, J. E.; JOHNSON, G. K. Periodontal and restorative considerations for crown lengthening. Quintessence Int., v. 16, n. 12, p. 833-836, Dec. 1985.

14 TRISTÃO, G. C. Espaço biológico: estudo histológico em periodonto clinicamente normal de humanos. São Paulo, 1992. 57 p. Tese (Doutorado). Faculdade de Odontologia de São Paulo - USP.

15 WAGENBERG, B. D.; ESKOW, R. N.; LANGER, B. Exposing adequate tooth structure for restorative dentistry. Int. J. Periodont. Res., v. 9, n. 5, p. 322-331, 1989.

16 WILSON, R. D.; MAYNARD, G. Intracrevicular restorative dentistry. Int J. Periodont. Res., v. 1, n. 4, p. 34-49, 1981.

Figura 1- Foto inicial, mostrando a hiperplasia do tecido gengival para o interior da cavidade cariosa 
Figura 2- Radiografia inicial

Figura 3- Restabelecimento das distâncias biológicas, após a osteotomia PUBLICATIO UEPG - Biological and Health Sciences, 6 (1): 89-101, 2000. 
Figura 4- Pós-operatório de 45 dias, término do preparo nítido

Figura 5- Restauração em amálgama - pós-operatório de 45 dias 
Figura 6- Radiografia após a restauração final 